\title{
РОССИЙСКИЕ АРХИВЫ И
}

\section{ПУБЛИЧНАЯ ДИПЛОМАТИЯ:}

\section{АКТУАЛИЗАЦИЯ ИСТОРИИ СОВЕТСКО-ЧЕШСКИХ ОТНОШЕНИЙ}

\author{
А.Н. Артизов \\ Федеральное архивное агентство
}

Автор обращается к проблеме роли и места архивов в процессе формирования политической идентичности, в том числе в области «политики памяти». В статье обращается внимание на то обстоятельство, что преобладающие представления об архивах подразумевают статичное понимание роли и функционирования архивов. Вместо этого автор предлагает рассматривать архивы как часть широкой сети институтов публичной дипломатии, которые формируют взаимопонимание и сотрудничество в гуманитарной сфере.

Для подтверждения заявленного тезиса статья обращается к деятельности российских архивов в рамках развития российско-чешских отношений. Особое внимание уделяется отражению в архивных документах двусторонних отношений в 1918, 1938 и 1968 гг. Автор делает вывод, что рассекречивание документов по проблемным вопросам двусторонних отношений не всегда приводит к единым оценкам и взаимопониманию, т.к. стороны могут иметь противоположные интерпретации одних и тех же документов.

Ключевые слова: открытость архивов, архивоведение, рассекречивание архивов, сборник архивных документов, российско-чешские отношения. 


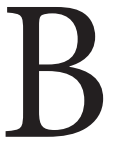

последние десятилетия в общественных науках обсуждается вопрос о том, как общественная дискуссия формирует социальное и политическое поведение, а также сознание и самосознание людей [15, p. 24-25]. Особое место в этой связи отводится архивам, которые начинают играть всё более важную роль в актуализации внутриполитических и межгосударственных дискуссий по исторической проблематике, в отборе, публичной демонстрации и сохранении документов, имеющих особое значение для этих дискуссий. Некоторые исследователи утверждают даже, что архивы - это не только хранители исторических документов, а монополисты «рынка памяти», главные производители общественной памяти [10, р. 21-22]. Достаточно вспомнить М. Фуко и его тезис о том, что архивы находятся в основании формирования культуры, они есть не что иное, как «закон» [8, с. 247-248]. Не менее влиятельны и вместе с тем критичны по отношению к архивам работы Ж. Деррида. Деррида, например, полагал, что архивы по своей природе находятся вне общественной коммуникации и совершают «насилие над природой», сохраняя то, чему суждено исчезнуть [12, р. 7]. Архивы предстают в подобных исследованиях одновременно как институт отбора и упорядочивания исторических данных и как нечто статичное, неизменное, выполняющее едва ли не онтологическую функцию для общества [8; 9; 11]. Задача настоящего исследования состоит в том, чтобы, напротив, продемонстрировать диалогичность архивов, их активное взаимодействие с обществом по определению и формированию целостной картины произошедших событий. В этом взаимодействии ключевыми условиями являются непредопределённость выводов, а также методологическая целостность полученных результатов. Это позволяет скорректировать вышеприведенный тезис о наличии скрытой (структурной или даже неосознанной) повестки дня у архивных учреждений, об их статичности. Вместе с тем формат статьи обуславливает более узкий исследовательский фокус, а именно рассмотрение деятельности российских архивов в сфере совместной российско-чешской исторической памяти, у которой в текущем году сразу три юбилея: 1918, 1938 и 1968 гг.

С теоретической точки зрения, исследование вписано в широкий контекст литературы, посвящённой феномену так называемой «публичной дипломатии». Данный феномен подразумевает активную работу обществ различных стран по укреплению взаимопонимания, формированию возможностей «услышать другого» [2; 3]. Публичная дипломатия вовлекает всё новые и новые силы, способствует возникновению площадок диалога и дискуссии, на которых медленно, но верно возникает общее взаимоуважительное понимание происходящего и прошлого [1; 5]. Среди многочисленных форматов не последнее место занимает сотрудничество между государственными и региональными архивами, проведение совместных выставок, публикационная деятельность. Пример тесного сотрудничества российских и чешских архивов по обнаружению и упорядочиванию сведений по сложным историческим проблемам, проблемам исторической памяти наглядно демонстрирует, что архивы вступают в открытый диалог, 
не боятся общественной критики и являются динамически развивающимися общественными институтами, которые формируют существенный потенциал для российской публичной дипломатии.

\section{Особенности российской архивной системы}

Важной стороной российского архивоведения является научно-просветительская и издательская деятельность архивистов. Ещё с досоветских времен, «архивары и архивашки» являлись не просто людьми, которые выдают пользователю документы и следят за их сохранностью. Лучшие из них были ещё и учёными-исследователями. Следуя этим традициям, российские архивы постоянно экспонируют документы, причём теперь всё больше на виртуальных выставках, в онлайн-режиме, много публикуют, готовят научные издания источников.

Для этой работы в современной России созданы все необходимые условия. Фактически и юридически сложилась практика свободного доступа к открытым источникам. С 1991 г. рассекречено около 10,5 млн дел (или примерно 125 тыс. м2 архивных полок). Когда последнего руководителя Главного архивного управления Советского Союза спрашивали о доступе в архивы, он обычно отвечал: «У нас архивы открыты с 9 утра до 6 вечера». В федеральных, региональных и муниципальных архивах современной России 98\% от общего числа учтённых документов открыты. По федеральным архивам эта цифра несколько ниже, здесь открыты примерно 96\%. Эти цифры не учитывают ведомственных архивов, где, как и во всем мире, действует особый порядок.

Рассекреченные комплексы архивных документов немедленно включаются в научный оборот, становятся доступными исследователям в читальных залах архивов, а широкой общественности - в том числе в виде подготовленных документальных сборников.

Сохраняется важный принцип в работе российских архивов - открытость. В то же время, с начала XXI в. работники архивов стали строже и более ответственно подходить к рассекречиванию, в полном объёме выполняя требования законодательства о государственной тайне. И в сравнении с «архивным романтизмом» 90-х гг. прошлого века, когда документы порой открывали, даже не потрудившись представить их экспертам, темпы рассекречивания снизились. Но это не означает, что можно говорить о закрытии архивов. Действует Межведомственная комиссия по защите государственной тайны, которая принимает решения о рассекречивании документов высших органов КПСС и Советского правительства, то есть тех органов, которые не имеют правопреемников; сами сотрудники архивов правами по рассекречиванию не обладают [4].

В подтверждение можно привести следующие цифры по федеральным архивам. В 2006-2010 гг. рассекретили 44 тыс. дел (каждое дело - это примерно 250 листов текста с оборотами), в следующем пятилетии в 2011-2015 гг. - 91,6 тыс. дел, в 2016-2017 гг. - более 15 тыс. дел. Причём эти цифры не учитывают объёмы 
рассекречивания архивных документов, которые выполняются в ведомствах. Только по Центральному архиву Министерства обороны в связи с выполнением приказа министра о рассекречивании документов Великой Отечественной войны рассекречены сотни тысяч дел.

\section{«Восьмёрочные юбилеи» на чешском направлении}

Работа российских архивистов всегда строилась и продолжает формироваться на системной плановой основе, специально не подстраиваясь под юбилеи. Тем не менее, нельзя не выделить 1918, 1938 и 1968 гг. в российско-чешских отношениях.

В отношении событий 1918 г. ведётся работа по организации выставок и публикации архивных документов - совместно с архивами Чехии и научно-исследовательским сообществом. Осенью 2008 г. в Москве в выставочном зале федеральных архивов демонстрировалась совместная с чешскими партнёрами историко-документальная выставка «Чехословацкий корпус в России. 19141920 гг.». На выставке экспонировались документы о формировании и деятельности чешско-словацких воинских формирований, начиная с возникновения Чешской дружины. Среди экспонатов была схема расположения эшелонов с легионерами от города Сердобска Саратовской губ. до города Владивостока, датируемая весной 1918 г. Разложенная в центре зала на огромном столе, эта схема наглядно показала какой длинный путь к дому прошли чехословацкие легионеры. Начав своё движение с территории Украины в 1917 г. по договоренности с Временным правительством, они покинули пределы России в 1920 г., подписав соглашение уже с представителями советской власти на Дальнем Востоке.

Именно выставка послужила основой для самостоятельной работы россиян над сборником документов по истории формирования и деятельности Чехословацкого корпуса в России с целью введения в научный оборот как можно более полного комплекса источников по этой теме.

Выявление документов проводилось по фондам пяти федеральных архивов и Архива внешней политики Российской империи МИД России. В чешских архивах по фондам Военно-исторического архива, входящего в состав Центрального военного архива Минобороны Чешской Республики, и Национального архива Чешской Республики. Значительную часть документов перевели на русский с чешского, французского, английского, немецкого языка.

На начальном этапе планировалось издать один том из двух разделов, первый - по дореволюционному, второй - советскому периоду. Однако в ходе работы выяснилось, что в отличие от событий Гражданской войны период Первой мировой войны в чешских архивах отражён неполно. С учётом этого было решено провести дополнительное выявление документов уже в российских архивах и более детально показать историю чехословацких воинских формирований в составе российской императорской армии. 
Масштаб проделанной работы иллюстрируют следующие цифры. В 2008 г. для выставки отобрали 114 документов за 1914-1917 гг., в сборник за этот же период включили 500 документов. Это позволило сформировать отдельный первый том.

Он освещает, прежде всего, организационную сторону создания чешскословацких воинских формирований в России в историческом контексте. В сборнике представлены позиции лидеров чешского и словацкого национальных движений, а также руководства внешнеполитического и военного ведомств России. Впервые комплексно опубликованы инициативные записки и ходатайства Союза чешско-словацких обществ в России, Отделения для России Чешско-словацкого национального совета (ЧСНС), а также отзывы и мнения на них российских чиновников. Публикуемые наградные материалы, отзывы военного командования отражают боевую деятельность и заслуги чешско-словацких воинских формирований.

Хронологические рамки первого тома охватывают период от начала Первой мировой войны по декабрь 1917 г., т.е. с момента возникновения самой идеи чешских и словацких воинских формирований в России до того времени, когда они были провозглашены неотъемлемой частью автономной Чехословацкой армии во Франции. Первый том вышел в свет в 2013 г.

В настоящее время завершается работа над вторым томом, который планируется издать в конце этого года. Он насчитывает порядка 600 документов, сгруппированных по четырём разделам:

1-й - так называемый «вооруженный нейтралитет» по отношению к советской власти (январь - май 1918 г.);

2-й - активные боевые действия против советских воинских формирований (май - ноябрь 1918 г.);

3-й - передислокация частей корпуса в тыл, привлечение его военнослужащих к охране Транссибирской железнодорожной магистрали (ноябрь 1918 г. - февраль 1920 г.);

4-й - окончательная эвакуация частей чехословацкого корпуса из России (февраль - ноябрь 1920 г.).

Впервые в научный оборот комплексно вводятся документы органов управления Красной и Белой армии, государственных и общественных организаций стран Антанты, переписка Чехословацкого национального совета (представительного органа руководства чехословацким национальным движением в России) с лидерами Советской России и правительствами стран Западной Европы и США. Также впервые документально, насколько это возможно, воссоздана история захвата российского золотого запаса в 1918 г. и его последующая передача чехословацким военным командованием в 1920 г. советским органам власти.

Вместе с готовящимся изданием двухтомника об адмирале Колчаке, видном морском офицере и лидере Белого движения, этот второй том, несомненно, будет вкладом российских архивистов в изучение Гражданской войны. 
В современной России продолжается поиск национальной идентичности с учётом собственного исторического опыта. И магистральное направление этого поиска лежит в русле не отрицания советской эпохи, а переосмысления её негативных явлений, в том числе противостояния между «белыми» и «красными» и завершения войны в умах соотечественников. Это, конечно, поистине сверхзадача, для достижения которой требуются напряжённые усилия, связанные не только с научным познанием прошлого, но и продолжением преобразований в стране, налаживанием качественной и комфортной жизни граждан. Новая российская идентичность также подразумевает единство и преемственность всех этапов отечественной истории - древнерусского, великокняжеского, имперского, советского, наконец, современного.

Не менее важные события для идентичности Чехии и отчасти России произошли в 1938 г. на Мюнхенской конференции Великобритании, Германии, Италии и Франции. «Мюнхенский сговор» стал кульминацией политики попустительства гитлеровской агрессии и способствовал в конечном итоге развязыванию Второй мировой войны.

Ещё два года назад российские архивисты и историки решили подготовить большую электронную публикацию с целью ввести в научный оборот дополнительный комплекс документов о том, как готовилось Мюнхенское соглашение. Хронологические рамки интернет-публикации «Накануне и после Мюнхена. Архивные документы рассказывают» ограничены 1937-1939 гг. Первой рубежной датой является ноябрь 1937 г. ${ }^{1}$. Вторая рубежная дата - март 1939 г., когда Чехословакия перестала существовать как суверенное государство, Мюнхенские соглашения были разорваны Берлином, и затем разразился политический кризис, предшествовавший нападению Германии на Польшу.

В публикацию включено почти 500 документов (в том числе 100 фотографий) из фондов российских федеральных и ведомственных архивов. Почти 60\% из них вводятся в научный оборот впервые, поскольку до недавнего времени имели грифы «секретно» и «совершенно секретно». Среди них записи бесед, протоколы совещаний, докладные и аналитические записки, обзоры, отчёты, справки, бюллетени, информационные письма, шифртелеграммы.

Основной массив русскоязычных документов существенно дополнен трофейными документами, которые были выявлены в фондах иностранного происхождения Российского военного архива. Иностранные документы переведены на русский язык с немецкого, польского, французского и английского языка. Это позволяет взглянуть на то, что происходило в Европе накануне Второй мировой войны, глазами не только советской стороны, но и других участников событий, поскольку публикация включает в себя как немецкие документы, так и документы, захваченные нацистами.

\footnotetext{
1 В начале ноября 1937 г. в Берлине состоялось совещание военного и политического руководства Третьего рейха, на котором было принято решение аннексировать Австрию и Чехословакию.
} 
В качестве примера можно привести цитату из записей бесед президента Чехословацкой республики Бенеша. В беседе с советским полпредом С.С. Александровским 18 мая 1938 г. он заявил, что даже если Чехословакии не будет оказана помощь, «она в состоянии драться, отступая на восток, три или четыре месяца». Отсутствие укреплений на границах с Польшей и Венгрией глава Чехословакии не посчитал опасным фактором: Польшу будет сдерживать Советский Союз, а Венгрию - Малая Антанта. Признавая возможность поражения от германского вермахта, он повторил: «Мы всё-таки будем драться, пробиваясь на восток, для соединения с Красной армией... Если понадобится, чехи не посчитаются для спасения своей армии ни с какими чужими границами и территориями». К сожалению, совсем другое Бенеш говорил за день до этого, 17 мая английскому послу Ньютону.

Наконец, в советско-чешской истории нельзя обойти стороной события «Пражской весны» 1968 г. По инициативе или с участием российских архивистов только за последние 10 лет подготовлены и изданы следующие сборники:

1. «Пражская весна и международный кризис 1968 г. Документы». Вена. 2008. На русском и немецком языках;

2. «Чехословацкий кризис 1967-1969 гг. в документах ЦК КПСС». Москва. Издательство РОССПЭН. 2010;

3. «Пражская весна» и международный кризис 1968 года». Т. 1 Исследования. Т. 2 Документы. Москва. Издательство фонда «Демократия». 2010.

В эти публикации полностью или частично включены документы из фондов Политбюро, Секретариата и аппарата ЦК КПСС, а также материалы международных совещаний руководителей коммунистических и рабочих партий, глав правительств - участников Варшавского договора. Кстати говоря, документальный комплекс международных совещаний руководителей стран социалистического лагеря, на которых принимались коллегиальные решения по чехословацким событиям, рассекречен. В МИД России основной архивный фонд по тематике 1968 г. также рассекречен.

Конечно, часть архивных документов ещё остаётся на закрытом хранении. В прессе не раз упоминалось заявление В.М. Фалина о телефонном разговоре Брежнева и Дубчека, якобы имевшем место 16 августа накануне ввода войск 21 августа 1968 г. Но это лишь аберрация памяти покойного Валентина Михайловича, ставшего невольным автором сенсации. Документально подтверждается, что имели место телефонные переговоры 13 августа, их текст давно известен и неоднократно публиковался. В них имеется фрагмент, позволяющий некоторым учёным трактовать позицию Дубчека как возможное согласие на советское военное вмешательство (в ответ на упрёк Брежнева, что чехословацкий лидер не исполняет взятые на себя обязательства, и это вынуждает советское руководство «по-новому оценивать обстановку и принимать новые самостоятельные меры», Дубчек раздраженно ответил: «Тов. Брежнев, принимайте все меры, которые ваше Политбюро ЦК считает правильными»). Косвенным доказатель- 
ством отсутствия контактов 16 августа является то, что о них ни разу не упоминают в последующих переговорах, в отличие от ссылок на телефонные переговоры 13 августа.

В целом, деятельность российских архивов и архивистов в вопросах рассекречивания и сохранения архивных документов, отражающих совместный исторический опыт России и Чехии, подразумевает, что архивы являются не столько монополистами «рынков памяти», сколько элементами разветвлённой сети учреждений и отдельных граждан, которые вместе ищут смыслы, которые, с одной стороны, отражают объективное состояние прошлого, а с другой - имеют практическое значение для формирования политических и исторических ориентиров в наше время. Основными инструментами публичной дипломатии архивов на российско-чешском направлении можно считать издание сборников архивных документов, организацию выставок по узловым памятным датам, использование возможностей новых технологий для демонстрации полученных результатов, а также попытки классифицировать архивные источники, провести первичную профессиональную обработку имеющихся документов - для последующего обсуждения историками и всеми заинтересованными сторонами. Пока участие в публичной дипломатии является сравнительно новым направлением работы российских архивов, несмотря на большое количество соглашений с зарубежными архивами. Но сама изменившаяся общественная и политическая обстановка и, в особенности, внедрение принципов открытости побуждают архивы России всё более активно включаться в различные форматы публичной дипломатии. Богатейшее документальное наследие российских архивов позволяет им вносить свой уникальный вклад в решение сложных исторических вопросов.

\section{Список литературы:}

1. Боришполец К.П. Ресурсы публичной дипломатии Союзного Государства России и Беларуси // Вестник МГИМО Университета. 2017. № 3 (54). С. 224-237.

2. Великая А.А. Публичная дипломатия как инструмент международного диалога // Международная жизнь. 2016. № 2. С. 154-164.

3. Долинский А.В. Дискурс о публичной дипломатии // Международные процессы. 2011. T. 9. № 25. С. 63-73.

4. Медведева О.В. Правовая и нормативно-методическая база архивного дела в России // Социально-экономические явления и процессы. 2014. № 1 (59). С. 143-148.

5. Смирнов Н.А. Публичная дипломатия: эволюция концепта в политической науке // Вестник Московского университета. Серия 12: Политические науки. 2015. № 1. С. 78-89.
6. Фуко М. Археология знания. СПб.: ИЦ «Гуманитарная академия»; Университетская книга, 2004. 416 с.

7. Цветков А.Ю. Публичная дипломатия как ресурс внешней политики: проблема эффективности // Вестник Санкт-Петербургского университета. Серия 6. Философия. Культурология. Политология. Право. Международные отношения. 2010. № 3. С. 110-116.

8. Blouinjr F.X. Archivists, Mediation, and Constructs of Social Memory // Archival Issues. 1999. Vol. 24. No. 2. Pp. 101-112.

9. Brothman B. Orders of Value: Probing the Theoretical Terms of Archival Practice // Archivaria. 1991. No. 32. Pp. 78-100.

10. Brown R.H., Davis-Brown R. The making of memory: the politics of archives, libraries and museums in the construction of national con- 
sciousness // History of the Human Sciences. 1998. Vol. 11. No. 4. Pp. 17-32.

11. Cook T. Archival Science and Postmodernism: New Formulations for Old Concepts // Archival Science. 2000. Vol. 1. No. 1. Pp. 3-24.

12. Derrida J. Archive Fever. The Freudian Impression. Chicago-London: The University of Chicago Press, 1996. 128 p.

13. Ketelaar E. Archives as spaces of memory //
Journal of the Society of Archivists. 2008. No. 29 (1). Pp. 9-27.

14. Lubar S. Information Culture and the Archival Record // American Archivist. 1999. No. 62 (1). Pp. 101-112.

15. Nesmith T. Seeing Archives: Postmodernism and the Changing Intellectual Place of Archives // The American Archivist. 2002. Vol. 65. No. 1. Pp. 24-41.

\title{
06 aвmope:
}

Андрей Николаевич Артизов - д.и.н., руководитель Федерального архивного агентства, действительный государственный советник Российской Федерации 1 класса. 115035, г. Москва, Софийская наб., д. 34, стр. 1. E-mail: rosarchiv@gov.ru.

\section{REVIEW OF RUSSIAN ARCHIVES ON SOVIET-CZECH RELATIONS}

\author{
A.N. Artizov \\ DOI 10.24833/2071-8160-2018-4-61-168-177 \\ Federal Archival Agency
}

The author addresses the problem of the role and place of archives in the process of political identity formation, including in the field of "politics of memory." The article draws attention to the fact that the prevailing notions about archives imply a static understanding of the role and functioning of archives. Instead, the author challenges those assumptions and suggests examining the archives as part of a wide network of institutions of public diplomacy, which forge and nurture mutual understanding and cooperation in the humanitarian sphere. To confirm the stated thesis, the article refers to the joint activities and activities of Russian archives in the framework of Russian-Czech relations, examines in detail the questions of historical memory and complex historical issues in the history of Russian-Czech relations. The article analyzes the current state of the archives on Soviet-Czech relations, the trends in the declassification of archival materials. Particular attention is given to the reflection of bilateral relations in archival documents in 1918, 1938 and 1968. The author concludes that the declassification of documents on problematic issues of bilateral relations does not lead to an automatic improvement of mutual understanding, since the parties may have conflicting interpretations of the same documents.

Key words: openness of archives, archival studies, declassification of archives, a collection of archival documents, Russian-Checz relations.

\section{References}

1. Borishpolets K.P. Resursy publichnoi diplomatii Soiuznogo Gosudarstva Rossii i Belarusi [Public diplomacy resources of Allied State of Russia and Belarus].
MGIMO Review of International Relations, 2017, no. 3 (54), pp. 224-237 (in Russian).

2. Velikaia A.A. Publichnaia diplomatiia 
kak instrument mezhdunarodnogo dialoga [Public diplomacy as instrument of international dialog]. Mezhdunarodnaia zhizn', 2016, no. 2, pp. 154-164 (in Russian).

3. Dolinskii A.V. Diskurs o publichnoi diplomatii [Discourse on public diplomacy]. International Trends, 2011, vol. 9, no. 25, pp. 63-73 (in Russian).

4. Medvedeva O.V. Pravovaia i normativno-metodicheskaia baza arkhivnogo dela v Rossii [Legal and normative methodological foundations of archive service in Russia]. Sotsial'no-ekonomicheskie iavleniia $i$ protsessy [Social and economic phenomena and processes], 2014, no. 1 (59), pp. 143-148 (in Russian).

5. Smirnov N.A. Publichnaia diplomatiia: evoliutsiia kontsepta $\mathrm{v}$ politicheskoi nauke [Public diplomacy: evolution of concept in political science]. Vestnik Moskovskogo universiteta. Seriia 12: Politicheskie nauki - Herald of Moscow state university. Political Science, 2015, no. 1, pp. 78-89 (in Russian).

6. Fuko M. Arkheologiya znaniya [Archeology of knowledge]. St. Petersburg, Gumanitarnaya akademiya, Universitetskaya kniga Publ., 2004. 416 p. (in Russian).

7. Tsvetkov A.Yu. Publichnaya diplomatiya kak resurs vneshney politiki: problema effektivnosti [Public diplomacy as a resource of foreign policy and its effectiveness]. Vestnik Sankt-Peterburgskogo universiteta. Seriya 6. Filosofiya. Kultur- ologiya. Politologiya. Pravo. Mezhdunarodnye otnosheniya - Herald of Sanct Petersburg University. Philosophy, Cultural Studies, Political Science, International Relations, 2010 , no. 3, pp. $110-116$ (in Russian).

8. Blouinjr F.X. Archivists, Mediation, and Constructs of Social Memory. Archival Issues, 1999, vol. 24, no. 2. pp. 101-112.

9. Brothman B. Orders of Value: Probing the Theoretical Terms of Archival Practice. Archivaria, 1991, no. 32, pp. 78-100.

10. Brown R.H., Davis-Brown R. The making of memory: the politics of archives, libraries and museums in the construction of national consciousness. History of the Human Sciences, 1998, vol. 11, no. 4, pp. 17-32.

11. Cook T. Archival Science and Postmodernism: New Formulations for Old Concepts. Archival Science, 2000, vol. 1, no. 1, pp. 3-24.

12. Derrida J. Archive Fever. The Freudian Impression. Chicago-London: The University of Chicago Press, 1996. 128 p.

13. Ketelaar E. Archives as spaces of memory. Journal of the Society of Archivists, 2008, no. 29 (1), pp. 9-27.

14. Lubar S. Information Culture and the Archival Record. American Archivist, 1999, no. 62 (1), pp. 101-112.

15. Nesmith T. Seeing Archives: Postmodernism and the Changing Intellectual Place of Archives. The American Archivist, 2002, vol. 65 , no. 1, pp. 24-41.

\section{About the author:}

Andrei N. Artizov - Doctor of Historical Sciences, Head of the Federal Archival Agency, State Class Councilor of the Russian Federation. Moscow, Sofiyskaya nab., 34, building 1, 115035. E-mail: rosarchiv@gov.ru. 